\title{
Produtividade e Crescimento Econômico na América Latina: A Abordagem da Fronteira de Produção Estocástica
}

\author{
- EMERSON MARINHO*
}

\author{
- Almir BitTencourT **
}

\begin{abstract}
RESUMO
Este artigo analisa o desempenho da produtividade total de fatores e discute a experiência de crescimento econômico na América Latina. Com este objetivo, estima-se uma função fronteira de produção estocástica na forma de uma translog, com efeitos de ineficiência técnica, para um painel de 19 países, no período de 1961 a 1990. Utilizando-se o índice de produtividade total de Malmquist, o crescimento da produtividade é decomposto em dois componentes: variação tecnológica e variação de eficiência técnica. Por meio desta técnica consegue-se quantificar a contribuição da produtividade ao crescimento da América Latina, identificar as fontes de ineficiência técnica de produção e compreender os fatores determinantes do desempenho das economias latino-americanas. Neste aspecto, examina-se o desempenho relativo do Brasil no contexto da região, identificando-se fatores de natureza comum e aspectos diferenciais marcantes. Entre outras conclusões, a mais relevante é a de que a performance da produtividade total dos fatores foi a principal razão do baixo crescimento econômico da América Latina.
\end{abstract}

\section{Palavras-Chave}

crescimento econômico, fronteira estocástica, produtividade total dos fatores

\begin{abstract}
This paper examines the aggregate productivity performance and discusses the economic growth experience in Latin America. A translog stochastic frontier is fitted with inefficiency effects to a panel of 19 Latin American countries for the period 196I to 1990. Estimate productivity growth is decomposed into two components: technological progress and efficiency change. We use Malmquist Index to calculate total productivity factor (TFP) change. Applying international data sets, this study aims to: (I) examine the contribution of productivity to economic growth in Latin America, (2) investigate the sources of technical inefficiency, and (3) shed some light on the perfomance among Latin America economies. With this framework we show that total productivity factor perfomance was the main reason for low growth of Latin America.
\end{abstract}

\section{KEY WORDS}

economic growth, stochastic production frontier, total productivity of factors

\author{
JEL CLASSIFICATION \\ C23, 040, 047, 054
}

\footnotetext{
+ Artigo originado de um projeto de pesquisa financiado pelo CNPq.

* Professor do Curso de Pós-Graduação em Economia - CAEN/UFC. Endereço para contato: Av. da Universidade, 2.700 - $2^{\circ}$ andar - CEP: 20.060-I8I - Fortaleza - Ceará. E-mail: emarinho@ufc.br.

* Professor do Departamento de Economia Aplicada da UFC e Pesquisador do CAEN/UFC. E-mail: almir@caen. ufc.br.

(Recebido em setembro de 2005. Aceito para publicação em julho de 2006).
} 


\section{INTRODUÇÃO}

Até os anos 1980, o modelo neoclássico de crescimento econômico, desenvolvido por Solow (1956), manteve uma sólida supremacia como instrumental analítico referencial sobre os fatores que explicariam o processo de crescimento da renda per capita no longo prazo e, como conseqüência, sobre os elementos determinantes dos grandes desníveis de renda entre países ricos e pobres. De acordo com esse modelo, a dinâmica do crescimento de longo prazo estaria associada ao progresso técnico que apresentaria características exógenas.

Admitindo-se a ocorrência de progresso técnico, verifica-se que a renda per capita dos países cresceria no longo prazo pelos deslocamentos do equilíbrio de estado estacionário para níveis cada vez mais elevados em razão da melhoria tecnológica. Por outro lado, o nível de renda per capita associado a um determinado equilíbrio de estado estacionário seria determinado pela taxa de crescimento da população, pela propensão a poupar e pelos parâmetros tecnológicos, inclusive a taxa de depreciação, todos considerados exógenos.

No caso de endogeneização da taxa de poupança, originada da contribuição de Ramsey (1928), Cass (1965) e Koopmans (1965) ao modelo neoclássico tradicional, o nível de renda per capita de equilíbrio estacionário resultaria dos parâmetros determinantes das preferências das famílias e da tecnologia, esta considerada exógena, bem como da dotação disponível de fatores de produção.

Empiricamente, a medida da contribuição do progresso técnico para o crescimento do produto per capita foi operacionalizada por Solow (1957), por meio do conceito de produtividade total dos fatores (PTF), com a utilização explícita da estrutura de uma função de produção Cobb-Douglas. Nesse artigo, o autor constata a ocorrência de significativo resíduo, medido pela diferença entre as taxas de crescimento do produto real e as taxas ponderadas de crescimento dos fatores de produção capital e trabalho.

A idéia do progresso técnico era, para Solow, uma expressão abreviada para qualquer deslocamento da função de produção. Estudos empíricos realizados com base na contabilidade do crescimento e inspiradas no modelo neoclássico apontaram, no entanto, para um conjunto de causas que poderiam estar associadas a tal fenômeno. Grande esforço de pesquisa foi, então, direcionado para introduzir na função de produção fatores que pudessem reduzir o valor do resíduo. ${ }^{1}$

A partir da publicação dos trabalhos de Romer (1986) e Lucas (1988) surgem modelos teóricos baseados na tradição de Arrow (1962) e Sheshinski (1967), sugerindo

1 Ver, a esse respeito, Griliches (1996) e Hulten (2000). 
uma maior contribuição do capital, no qual se inclui o capital humano, para o crescimento econômico. A interpretação desses modelos é que a variação tecnológica e os novos conhecimentos assumem papel central no processo de acumulação de capital e do crescimento.

$\mathrm{O}$ argumento central contido nas mencionadas proposições é que o investimento em capital, abrangendo capital físico e humano, gera externalidades positivas (spillovers) que elevam a capacidade produtiva das empresas responsáveis pelos investimentos e contribuem para aumentar a capacidade produtiva de outras empresas, assim como dos outros trabalhadores. Desse modo, o estoque de capital físico representaria um indicador do conhecimento acumulado e de experiência na forma learning-by-doing, cujas externalidades resultariam em rendimentos crescentes em termos da economia agregada. (Romer, 1986). O capital humano poderia também gerar externalidades que levariam a rendimentos crescentes na função de produção agregada. (Lucas, 1988).

Não obstante as diferenças nos argumentos e previsões das principais teorias de crescimento econômico, há concordância na literatura empírica de que a acumulação de capital físico não é capaz de sustentar o crescimento por períodos prolongados de tempo, em face dos rendimentos decrescentes, e que a fonte para a evolução e a prosperidade econômica, no longo prazo, reside na expansão da produtividade total dos fatores (PTF). (Senhadji, 1999; Easterly e Levine, 2001). A melhoria do bem-estar da população, em termos agregados, pode ser influenciada pelo crescimento econômico por meio da produtividade.

Este artigo tem como objetivo básico examinar a contribuição da variação da PTF para o crescimento econômico de uma amostra de 19 países da América Latina, no período de 1961 a 1990, verificando-se, também, o desempenho relativo do Brasil no contexto da região de forma a identificarem-se elementos de natureza comum a todos os países da região e os fatores que os diferenciam. Para isso, utiliza-se a abordagem da fronteira estocástica de produção, que é modelada com a incorporação de efeitos de ineficiência técnica, expressas por um vetor de variáveis macroeconômicas consideradas relevantes na sua explicação. Essas variáveis relacionam-se ao ambiente local e à política econômica de cada país.

Na quantificação e análise da evolução da produtividade, a abordagem da fronteira estocástica de produção permite a análise dos países, a partir da identificação de suas posições em relação à fronteira de produção da região e avaliação de seu desempenho relativamente às mudanças verificadas dessa fronteira ao longo do tempo. Como resultado, tem-se o ranking qualitativo dos países da amostra em relação à fronteira de produção e a quantificação de suas medidas de eficiência técnica. 
A metodologia utilizada no cálculo da variação da PTF e de sua decomposição baseia-se no índice de produtividade total de Malmqüist. A PTF é decomposta em dois componentes: variação de eficiência técnica e variação técnológica. Este procedimento de decomposição permite identificar e quantificar os fatores determinantes do desempenho da PTF ao longo do tempo: o componente que explica uma aproximação da fronteira de produção (variação de eficiência técnica) e aquele relativo ao deslocamento da própria fronteira de produção (variação tecnológica).

Esse procedimento de mensuração da PTF difere das abordagens tradicionais, representadas pela contabilidade de crescimento (Solow, 1957 e Denison, 1972), e pelas medidas baseadas em números índices (Divisia e Törnqvist), porque nessas abordagens se considera a hipótese de que todas as unidades produtivas são eficientes, de modo que o crescimento da produtividade é interpretado como um movimento da fronteira de produção (variação tecnológica). Existindo ineficiência técnica, a estimação do progresso técnico, consoante esses métodos, resultaria em uma medida viesada. Além disso, mesmo que as unidades produtivas sejam eficientes sob o aspecto técnico, ainda assim poderá existir viés na medida do progresso técnico em face de possíveis ineficiências alocativas. (Grosskopf, 1993).

Tendo como base a literatura sobre produtividade originada dos trabalhos de Fried, Lovell e Schmidt (1993), Battese e Coelli, (1995) e Coelli, Rao e Battese (1998), modela-se a forma funcional da fronteira de produção a partir dos dados da amostra. Trata-se, portanto, de um procedimento distinto daquele utilizado pela literatura tradicional de estimação da PTF.

$\mathrm{O}$ artigo se distribui, além da introdução, em mais cinco seções. A seção 1 faz um breve relato das políticas econômicas adotadas na América Latina e de seus resultados, os quais motivaram este estudo. A seção 2 apresenta o modelo econométrico a ser estimado e explicita os procedimentos de estimação do índice de produtividade total de Malmqüist. A seção 3 define a base de dados e as variáveis empregadas, além de analisar os resultados das estimações. A seção 4 trata do índice de variação da produtividade total (PTF) de Malmqüist e de sua decomposição em variação de eficiência técnica e variação tecnológica. A última seção é dedicada às conclusões.

\section{AMÉRICA LATINA: CRESCIMENTO, CRISE E REFORMAS}

Nos anos 1950, por força da influência das proposições de política emanadas da Comissão Econômica para a América Latina (CEPAL), a maioria dos países da região adotou como estratégia de desenvolvimento local o modelo de industrialização por substituição de importações (ISI). Esta estratégia tinha como eixos centrais a implan- 
tação de indústrias voltadas para o mercado interno e a instituição de instrumentos de proteção da indústria nascente contra a concorrência externa, concretizados por meio de mecanismos tarifários e não-tarifários e da concessão de subsídios.

A expansão local das atividades da indústria nascente, por outro lado, demandava uma crescente intervenção direta do Estado na economia, a fim de que fossem eliminados os "estrangulamentos" de infra-estrutura e de serviços então diagnosticados como fatores impeditivos da expansão da atividade produtiva, notadamente de cunho industrial. Identificava-se a indústria como o setor dinâmico da economia, capaz de impulsionar o crescimento econômico e reverter, na concepção cepalina, a forte dependência externa. ${ }^{2}$ Essa dependência materializava-se na constatação de que ocorria um processo histórico de deterioração das relações de troca envolvendo o centro (países ricos) e os países periféricos (subdesenvolvidos).

Apesar de o pensamento econômico vigente estar predominantemente em consonância com as idéias da CEPAL, sobretudo em relação à necessidade de uma forte intervenção do Estado na economia, havia uma minoria de economistas que rejeitava o ISI, baseados nos argumentos da liberdade econômica, no pouco intervencionismo e na austeridade monetária. ${ }^{3}$ De acordo com os monetaristas latino-americanos, o processo inflacionário, que contaminava a maior parte dos países da região, poderia ser explicado justamente pelo excesso de gastos governamentais necessários à sustentação das ineficiências introduzidas pela ISI. Com a elevada inflação, os juros reais eram comprimidos, gerando um forte desestímulo à geração de poupança privada, o qual afetava negativamente a formação de capital e, portanto, o crescimento econômico.

O câmbio sobrevalorizado, por outro lado, introduzia ineficiências adicionais na utilização dos recursos, levando as indústrias a uma baixa capacidade de competição internacional, cuja sobrevivência era garantida pelo excesso de protecionismo tarifário e não-tarifário, assim como de subsídios oferecidos às indústrias. (Reinhardt e Peres, 2000).

No final dos anos 1960, a industrialização baseada na substituição de importações começa a mostrar o esgotamento de suas possibilidades no sentido de promover transformações radicais em toda a economia da região. Iniciam-se as críticas no interior da própria CEPAL, e fora dela, sobre os resultados do processo de industrialização

2 De acordo com o pensamento de Raul Presbich, principal formulador das políticas de intervenção sugeridas pela CEPAL, o grande diferencial de produtividade existente entre os países do centro e os da periferia deveria ser reduzido, ao menos numa primeira etapa, por meio da importação de bens de capital, portadores por excelência do progresso técnico. Embora o progresso técnico tenha sido reconhecido como fator impulsionador do crescimento econômico nos estudos iniciais da CEPAL, a ênfase inicial é dirigida para a acumulação de capital. Veja-se e esse respeito Bernardo Gouthier Macedo. As idéias de Raúl Prebisch sobre a industrialização periférica:1949-1954. 1994. Dissertação (Mestrado), Campinas: IE/Unicamp, São Paulo, mimeo.

3 No Brasil, Eugênio Gudin era um dos expoentes dessa corrente de pensamento. 
iniciado nos anos 1950. Uma das razões apontadas para essa constatação residia na diagnosticada dependência tecnológica, em face do modelo de industrialização adotado, que se orientou para a produção de bens de consumo duráveis destinados ao atendimento da demanda dos segmentos de rendas alta e média da população. As tecnologias utilizadas nesse tipo de indústria já eram disponíveis e controladas pelos países desenvolvidos.

A aceleração da inflação e a redução das taxas de crescimento, presentes na maioria dos países da região, após a crise do petróleo de 1973, levaram ao fortalecimento da posição dos críticos ao modelo de ISI, surgindo a partir de então proposições de política que alterariam radicalmente o padrão adotado a partir dos anos 1950. Os objetivos dessas recomendações não se limitavam apenas aos aspectos relacionados com a estabilização econômica, mas iam além ao formularem a proposição de uma completa transformação da estrutura produtiva, por meio da redução da intervenção do Estado na economia, liberalização e abertura comercial. A maior parte dessas medidas integrava o receituário das agências internacionais como condição para concessão de ajuda financeira. ${ }^{4}$ (Reinhardt e Peres, 2000).

Os três países da região que iniciaram, por volta da metade dos anos 1970 (Foxley, 1983 e Ramos, 1988), a implementação das reformas preconizadas foram Argentina, Uruguai e Chile. O programa de reformas incluía políticas de liberalização do mercado interno, privatização, abertura comercial, redução das restrições aos fluxos financeiros internacionais e a redefinição da atuação do Estado em setores econômicos. Os resultados nas economias desses países foram, no entanto, comprometidos pela crise da dívida externa que se abateu fortemente sobre toda a região no início dos anos 1980.

A referida crise decorreu, inicialmente, dos imensos desajustes no setor externo dos países importadores de petróleo proporcionados pelos choques de oferta ocorridos em 1973 e 1979. Em um primeiro instante, a farta disponibilidade de crédito barato, decorrente do volume de dólares acumulados pelos países produtores de petróleo, permitiu a solução do financiamento desses desajustes por meio de um maior endividamento a taxas de juros flutuantes. Mas a partir de 1981, a política monetária adotada pelos Estados Unidos com o objetivo de combater a inflação interna passou a manifestar-se vigorosamente contracionista, resultando na elevação das taxas de juros

4 Os programas de ajustamento estrutural constituíram o núcleo das reformas coordenadas por meio da colaboração entre o Fundo Monetário Internacional (FMI) e o Banco Mundial (BIRD) e se referiam a medidas recomendadas por essas instituições internacionais como precondição para a concessão de empréstimos aos países. 
internacionais, que levou ao acentuado crescimento da dívida dos países tomadores de empréstimos e à recessão econômica mundial. ${ }^{5}$

Nos anos 1980, muitos países endividados são impelidos a implementar os programas de ajustamento econômico promovidos sob auspícios do Fundo Monetário Internacional (FMI). Na América Latina, por volta da metade dos anos 1980, Bolívia, Costa Rica e México incorporam-se ao conjunto de países que já haviam adotado medidas direcionadas para as reformas econômicas. A Argentina retoma as ações reformadoras iniciadas em meados da década de 1970, mas paralisadas por força da crise da dívida externa, somente no final da década de 1980. Peru e Venezuela juntamse também à Argentina no mesmo período. O Brasil foi o último país de expressão econômica na região a se incorporar ao elenco de reformas conduzidas sob os mesmos objetivos, o que ocorreu no início dos anos 1990, embora tenha igualmente se socorrido da ajuda financeira do FMI por toda a década anterior. A partir de então é que se verifica também um impulso concreto em direção à abertura comercial da economia brasileira.

Não obstante todo o esforço de diversificação da estrutura econômica e as transformações ocorridas no setor produtivo, pode-se observar na Tabela 1 que a América Latina apresentou um baixo desempenho em termos de taxas de crescimento do produto per capita no período de 1960 a 1990, cerca de 1,23\% ao ano para a amostra de países utilizada neste trabalho, se comparado com o crescimento dos países do Leste da Ásia, $5,1 \%$, e da economia mundial, de 2,13\% ao ano. Mesmo os países ricos, integrantes da Organização para a Cooperação e Desenvolvimento Econômico (OCDE), foram capazes de manter altas taxas médias de crescimento no período, contrariando as previsões da hipótese de convergência ${ }^{6}$ das rendas per capita. Os melhores desempenhos da região verificaram-se nas décadas de 1960 e 1970. Já os anos 1980 foram marcados por forte recessão econômica.

5 A moratória do México, ocorrida em agosto de 1982, desencadeou a chamada crise da dívida como conseqüência da retração do crédito internacional e da grande elevação dos prêmios de risco.

6 Uma das qualificaçóes dessa hipótese refere-se ao conceito de convergência condicional que corresponde à previsão de que a taxa de crescimento da renda per capita de um país será positivamente relacionada à distância que o separa de seu próprio equilíbrio estacionário ou, ainda, que a convergência das rendas per capita entre países verificar-se-á para estados estacionários que configuram características estruturais similares. Veja-se a esse respeito, por exemplo, Barro e Sala-I-Martin (1995). 
TABELA I - TAXAS DE CRESCIMENTO DO PRODUTO PER CAPITA DA AMÉRICA LATINA E DE OUTRAS REGIÕES

\begin{tabular}{lcccc}
\hline PAÍSES/REGIÕES & $1960-1970$ & $1970-1980$ & $1980-1990$ & $1960-1990$ \\
\hline Argentina & 2,40 & 1,40 & $-3,20$ & 0,20 \\
Bolívia & 3,80 & 1,80 & $-1,80$ & 1,27 \\
Brasil & 3,20 & 5,90 & $-0,60$ & 2,83 \\
Chile & 2,30 & 0,80 & 1,10 & 1,40 \\
Colômbia & 2,40 & 3,20 & 1,10 & 2,23 \\
Costa Rica & 3,30 & 2,50 & $-0,60$ & 1,73 \\
República Dominicana & 2,50 & 4,30 & $-0,80$ & 2,00 \\
Equador & 2,00 & 6,10 & $-1,60$ & 2,17 \\
El Salvador & 2,40 & 1,10 & $-1,00$ & 0,83 \\
Guatemala & 2,00 & 2,40 & $-1,90$ & 0,83 \\
Honduras & 1,80 & 2,10 & $-1,00$ & 0,97 \\
Jamaica & 4,10 & $-1,10$ & 0,70 & 1,23 \\
México & 3,50 & 4,30 & $-0,40$ & 2,47 \\
Nicarágua & 3,90 & $-2,40$ & $-3,50$ & $-0,67$ \\
Paraguai & 1,70 & 6,20 & $-1,70$ & 2,07 \\
Peru & 3,10 & 0,50 & $-2,70$ & 0,30 \\
Trinidad e Tobago & 1,90 & 5,20 & $-3,50$ & 1,20 \\
Uruguai & 0,40 & 2,10 & $-1,00$ & 0,50 \\
Venezuela & 2,00 & $-0,50$ & $-2,00$ & $-0,17$ \\
\hline América Latina (19) & 2,56 & 2,42 & $-1,29$ & 1,23 \\
\hline África - Subsaara (17) & 2,10 & 1,10 & $-0,80$ & 0,80 \\
Países do Leste da Ásia (8) & 4,70 & 6,00 & 4,60 & 5,10 \\
OCDE* (22) & 4,30 & 2,50 & 2,10 & 2,97 \\
Economia Mundial (81) & 3,20 & 2,60 & 0,60 & 2,13 \\
\hline Fon Per & & & &
\end{tabular}

Fonte: Penn World Table 6.1 e Banco Mundial.

* Sigla em português do grupo de países ricos integrantes da Organization for Economic Cooperation and Development (OECD).

Uma questão emerge da observação dos dados: como explicar o modesto crescimento econômico da América Latina num período relativamente longo de tempo, e particularmente de um país como o Brasil que durante a década de 1970 manteve elevadas taxas de crescimento do produto, mas ingressa num longo período de baixo dinamismo econômico a partir da década seguinte? A resposta a essa questão deve ser buscada no exame do comportamento da PTF, uma vez que esta constitui o fator determinante do crescimento econômico no longo prazo, o que é feito nas seções seguintes, verificando-se também, separadamente, a contribuição de seus componentes de variação de eficiência técnica e de variação tecnológica. A identificação das fontes do crescimento econômico permite, portanto, uma melhor compreensão do dinamismo econômico dos países ao longo do tempo. 


\section{MODELO EMPÍRICO}

\subsection{Fronteira de Produção Estocástica}

O procedimento adotado como ponto de partida do cálculo da PTF reside na utilização do método paramétrico conhecido como análise de fronteira estocástica de produção. Este método foi proposto simultaneamente por Aigner, Lovell e Schmidt (1977) e Meusen e Broeck (1977).?

Uma de suas vantagens reside na incorporação, além dos distúrbios aleatórios relativo à função de produção, de efeitos de ineficiência técnica ao contrário dos métodos não paramétricos, que atribuem à ineficiência técnica os desvios do produto observado em relação ao produto potencial.

Mas, por outro lado, o método de fronteira estocástica requer a especificação de uma forma funcional da fronteira de produção e o indispensável estabelecimento de hipóteses distribucionais sobre os componentes dos distúrbios e da ineficiência técnica.

Utilizando dados em painel para uma amostra de 19 (dezenove) países latino-americanos, no período de 1961 a 1990, a forma funcional da fronteira estocástica foi determinada por meio de um teste de adequação (teste de máxima verossimilhança). Testou-se a hipótese nula de uma fronteira translog contra a alternativa de uma CobbDouglas. ${ }^{8}$ Em face do resultado do teste, adotou-se a função de fronteira de produção translog especificada na forma:

$$
\begin{aligned}
& \ln Y_{i t}=\alpha_{i}+\theta_{1} t+\frac{1}{2} \theta_{2} t^{2}+\left(\beta_{0}+\beta_{1} t\right) \ln K_{i t}+\left(\lambda_{0}+\lambda_{1} t\right) \ln L_{i t}+\frac{1}{2}\left[\eta_{1}\left(\ln K_{i t}\right)^{2}+2 \eta_{2} \ln K_{i t} \ln L_{i t}+\right. \\
& \left.+\eta_{3}\left(\ln L_{i t}\right)^{2}\right]+v_{i t}-u_{i t}
\end{aligned}
$$

em que as variáveis $Y_{i t}, L_{i t}$ e $K_{i t}$ representam, respectivamente, o produto, o trabalho e o estoque de capital físico em determinado período de tempo, $t$, de cada um dos países

7 Posteriormente, as contribuições de Forsund, Lovell e Schmidt (1980), Schmidt (1986), Bauer (1990), Battese (1992), Greene (1993), Battese e Coelli (1995) permitiram o aprimoramento do método, possibilitando sua implementação com dados em painel e com a incorporação da modelagem do componente de ineficiência técnica de produção.

8 Duffy e Papageorgiou (2000) rejeitam a especificação Cobb-Douglas usando um painel de dados para 82 países em um período de 28 anos. Examinando o impacto da tecnologia de produção sobre a eficiência técnica, Kneller e Stevens (2002) rejeitam a especificação da função de produção agregada na forma Cobb-Douglas em favor da translog e concluem que o efeito da forma funcional sobre as medidas de eficiência é muito pequeno. A função de produção translog constitui uma forma funcional mais flexível e é uma aproximação local para qualquer fronteira de produção. $\mathrm{O}$ resultado do teste apresentado na Tabela 3 foi a favor da forma funcional translog. 
da amostra. Os parâmetros $\alpha_{i}$ incorporam ao modelo os efeitos fixos com o objetivo de capturar heterogeneidades não observadas na amostra de países, principalmente relacionadas às diferenças iniciais nos níveis tecnológicos. A variável $v_{i t}$ representa os distúrbios aleatórios da função de produção que, por hipótese, segue uma distribuição normal com média zero e variância constante $\sigma_{v}^{2}$.

Além disso, acrescenta-se uma tendência determinística na fronteira de produção, de acordo com o termo $\theta_{1} t+(1 / 2) \theta_{2} t^{2}$, seguindo um procedimento usual nos trabalhos que utilizam essa metodologia. Os parâmetros $\alpha_{i}, \theta_{i}, \beta_{j}, \lambda_{k}, \eta_{l}$, associados às variáveis acima descritas, serão estimados econometricamente.

O termo $u_{i t}$, representando a ineficiência técnica de produção, é sempre não negativo. Em (1), $u_{i t}$ é modelado como:

$$
u_{i t}=\delta z_{i t}+\omega_{i t}
$$

em que $z_{i t}=\left(z_{1 t}, z_{2 t}, z_{3 t}, z_{4 t}\right)$ é um vetor de variáveis que explicam a ineficiência técnica, e $\delta$ um vetor de parâmetros associado a $Z_{i t}$, a serem estimados. Desde que, por hipótese, $\omega_{i t}$ tem distribuição $N\left(0, \sigma_{w}^{2}\right)$, a ineficiência técnica $u_{i t}$, também por hipótese, é independentemente distribuída (mas não identicamente distribuída), com distribuição normal truncada em zero com média $\delta z_{i t}$, e variância constante $\sigma_{u}^{2}$.

Os componentes do vetor $z_{i t}$ são os seguintes:

$z_{1 t}$ - representa o gasto com o consumo do governo em relação ao produto interno de cada país. Trabalhos empíricos têm sido realizados com o intuito de quantificar o efeito do tamanho do governo, e em particular os gastos com despesa corrente, sobre o crescimento econômico, a alocação dos recursos e a eficiência agregada. Landau (1983) e Kormendi e Meguire (1985) encontram em seus artigos uma correlação negativa entre o tamanho do setor público e o crescimento econômico para uma amostra de países. Scully (1989) conclui que a dimensão da participação relativa do governo na economia é negativamente correlacionada com a eficiência econômica e com as mudanças interperíodos na eficiência, de modo que países com grande participação do governo na economia apresentam um produto per capita menor se comparados com aqueles nos quais essa participação é menos significativa. Klein e Luu (2001), usando a técnica de fronteira estocástica de produção, estimam o tamanho ótimo das despesas correntes do governo em cerca de $30 \%$ do produto interno bruto para um painel de 39 países, no período de 1975 a 1990, e concluem que acima dessa porcentagem passa-se a observar um efeito adverso sobre a ineficiência técnica agregada. Assim, espera-se 
que o aumento do gasto do governo em custeio deve contribuir para o aumento de ineficiência técnica de produção;

$z_{2 t}$ - é o logaritmo da unidade mais a taxa de inflação, $\pi$, ou seja, ln $(1+\pi)$. Esta expressão considera os efeitos não-lineares da inflação sobre a ineficiência técnica. (De Gregório, 1992). ${ }^{9}$ É de se esperar que a inflação aumente a ineficiência técnica de produção;

$z_{3 t}$ - é o desvio do nível de preços local em relação à paridade do poder de compra (PPP), tomando-se os Estados Unidos da América como país de referência. A sua inclusão tem como objetivo controlar os efeitos das políticas de comércio que implementam desvalorizações no câmbio real sobre a ineficiência técnica. Um crescimento nos desvios dos preços locais em relação à PPP significa desvalorização no câmbio real (Miller e Upadhyay, 2000);

$z_{4 t}$ - é o grau de abertura, medido pelo valor da soma das importações e exportações em relação ao produto interno bruto de cada país. Espera-se, em geral, que economias mais abertas tenham maior acesso à importação de bens intermediários mais baratos, uma maior penetração a amplos mercados e a tecnologias mais avançadas. (Miller e Upadhyay, 2000). ${ }^{10}$ A implicação disso é que quanto maior o grau de abertura menor deveria ser o efeito de ineficiência técnica de produção.

A adoção da hipótese de retornos constantes de escala na função de produção (1), implica as seguintes restrições sobre os parâmetros desta função: $\beta_{0}+\lambda_{0}=1, \beta_{1}+\lambda_{1}=0, \eta_{1}+\eta_{2}=\eta_{2}+\eta_{3}$. Estas restrições são necessárias para permitir a construção do índice de produtividade de Malmqüist. (Färe et al., 1994).

A estimação simultânea e eficiente dos parâmetros das equações (1) e (2) é feita pelo método da máxima verossimilhança que, assim, permite calcular as magnitudes das eficiências técnicas para cada um dos países da amostra. Para efeito de estimação destes parâmetros, utilizou-se o programa Frontier 4.1 (Coelli, 1996), no qual a função de log-verossimilhança é expressa em termos da parametrização especificada por $\gamma=\sigma_{u}^{2} /\left(\sigma_{u}^{2}+\sigma_{v}^{2}\right)$. Este procedimento, proposto por Battese e Coelli (1993), facilita o processo de maximização por iterações, uma vez que o referido parâmetro possui valores situados entre zero e a unidade. Além do mais, a estatística $\gamma$ pode ser utilizada

9 Como em alguns países da região ocorreram períodos de deflação e também processos hiperinflacionários, adotou-se essa expressão a fim de se atenuar a influência das situações extremas sobre o termo da ineficiência.

10 A crítica central à utilização dessa variável, na forma especificada, decorre de sua provável endogeneidade nos modelos de equações de crescimento. No entanto, no presente modelo essa crítica não procede porque as equações (1) e (2) são estimadas simultaneamente pelo método de máxima verossimilhança. 
para testar a significância da inclusão dos efeitos de ineficiência técnica na função de produção (1)..$^{11}$

\subsection{Decomposição da Produtividade Total dos Fatores}

Para o caso de um único produto e um único insumo, pode-se mostrar que o índice de produtividade total decompõe-se nos componentes de variação de eficiência técnica (VET), variação de escala e variação tecnológica (VT). (Coelli, Rao, Battese, 1998). É evidente que no caso de retornos constantes de escala esta decomposição somente se dá em termos de variação de eficiência técnica e variação tecnológica.

Esta decomposição ao longo do tempo pode ser ilustrada graficamente como na Figura 1. ( Wu, 2000). Os pontos $\mathrm{a}_{1}$ e $\mathrm{a}_{2}$ correspondem aos níveis de produto observados $\mathrm{y}_{1} \mathrm{e} \mathrm{y}_{2}$, relativos à tecnologia nos períodos de tempo 1 e 2 e produzidos utilizando os insumos $\mathrm{x}_{1}$ e $\mathrm{x}_{2}$, enquanto $\mathrm{b}_{1}$ e $\mathrm{b}_{2}$ correspondem aos produtos potenciais $y_{1}^{f}$ e $y_{2}^{f}$. As diferenças entre os níveis de produtos potenciais, situados sobre a fronteira de produção, e os produtos observados constituem indicadores das eficiências técnicas de produção.

\section{FIGURA I - DECOMPOSIÇÃO DO CRESCIMENTO DO PRODUTO}

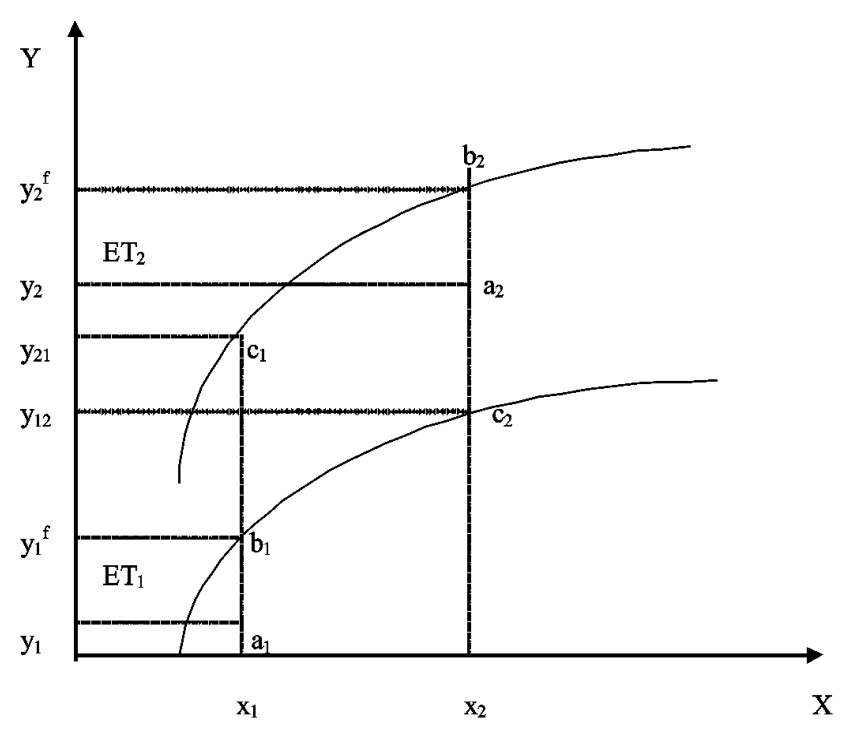

$11 \mathrm{O}$ valor de $\gamma$ próximo de zero, menor será a importância do componente da ineficiência técnica na explicação dos desvios observados da fronteira de produção. Quando seu valor aproximar-se de um, maior a importância da ineficiência técnica nos desvios da fronteira de produção. 
Assim, relativamente aos insumos $\mathrm{x}_{1} \mathrm{ex}_{2}$, as eficiências técnicas $E T_{1}$ e $E T_{2}$ são definidas, respectivamente, por $E T_{1}=\left(y_{f}^{1}-y_{1}\right)$ e $E T_{2}=\left(y_{f}^{2}-y_{2}\right)$. Nestes termos, pode-se decompor a variação do produto como:

$$
\Delta y=y_{2}-y_{1}=\left(y_{2}^{f}-E T_{2}\right)-\left(y_{1}^{f}-E T_{1}\right)=\left(y_{2}^{f}-y_{1}^{f}\right)+\left(E T_{1}-E T_{2}\right)
$$

Somando e subtraindo na expressão anterior, $y_{12}$, encontra-se:

$$
\Delta y=\left(y_{2}^{f}-y_{12}\right)+\left(y_{12}-y_{1}^{f}\right)+\left(E T_{1}-E T_{2}\right)
$$

em que $y_{12}$ é o nível máximo de produto produzido com o insumo $x_{2}$, relativo à tecnologia no período de tempo 1 .

Portanto, a variação no produto $\Delta y=\left(y_{2}-y_{1}\right)$ é decomposta em VT, $\left(y_{2}^{f}-y_{12}\right)$, em variação de escala de produção $\left(y_{12}-y_{1}^{f}\right)$, e em VET, $\left(E T_{1}-E T_{2}\right)$. No caso de retornos constantes de escala, a variação na PTF é definida somente pela soma dos componentes de VT e VET. Com efeito, como neste caso não existe variação de escala, seria indiferente produzir $y_{12}$ usando o insumo $x_{1}$, ou produzir $y_{1}^{f}$ usando o insumo $x_{2}$. Nestes termos, $\left(y_{12}-y_{1}^{f}\right)=0$. Na Figura 1 , a fronteira de produção seria linear e em qualquer ponto sobre esta curva a produtividade média do insumo $x$ seria constante, não havendo nem ganhos nem perdas de escala.

Observa-se, portanto, que nessas medidas está implícita a noção de distância que será usada no cálculo da PTF e de seus componentes. Assim sendo, como o índice de produtividade total de Malmqüist é calculado utilizando o conceito de função distância, apresenta-se na próxima seção uma breve discussão sobre esta medida.

\subsection{Função Distância}

Para se calcular a produtividade total dos fatores, por meio do índice de Malmqüist, faz-se necessário usar o conceito de função distância. Neste sentido, faz-se a seguir uma discussão sobre este conceito.

O conjunto de possibilidades de produção, para um dado período de tempo, $t$, representa o conjunto de todos os vetores de produtos $y^{t}=\left(y_{1}^{t}, y_{2}^{t}, \ldots \ldots, y_{M}^{t}\right) \in R_{+}^{M}$, que pode ser produzido com o vetor dos insumos $x^{t}=\left(x_{1}^{t}, x_{2}^{t}, \ldots \ldots, x_{N}^{t}\right) \in R_{+}^{N}$. Em outras palavras, é o conjunto de todas as combinações de insumos e produtos factíveis. Em 
termos formais, para um determinado período de tempo $t$, define-se conjunto de possibilidades de produção, $P\left(x^{t}\right)$, como:

$$
P\left(x^{t}\right)=\left\{\left(x^{t}, y^{t}\right): x^{t} \text { possa produzir } y^{t}\right\}
$$

A função distância orientada pelo produto ${ }^{12}$ pode ser definida utilizando o conceito do conjunto de possibilidades de produção (3). Denotando a função distância orientada pelo produto por $D_{o}^{t}\left(x^{t}, y^{t}\right)$, para um período de tempo $t$, uma definição mais formal é expressa por:

$$
D_{o}^{t}\left(x^{t}, y^{t}\right)=\operatorname{Inf}\left\{\left(\delta:\left(x^{t}, y^{t} / \delta\right) \in P\left(x^{t}\right)\right\}\right.
$$

Essa função mede a máxima expansão proporcional do produto observado necessária para garantir a igualdade entre ele e o produto potencial máximo, determinado pela fronteira do conjunto de possibilidades de produção $P\left(x^{t}\right)$.

A função distância $D_{o}^{t}\left(x^{t}, y^{t}\right)$ caracteriza completamente a tecnologia, de tal modo que $D_{o}^{t}\left(x^{t}, y^{t}\right) \leq 1$, se e somente se $D_{o}^{t}\left(x^{t}, y^{t}\right) \in P\left(x^{t}\right)$. Além do mais, $D_{o}^{t}\left(x^{t}, y^{t}\right)=1$, se e somente se a observação situa-se sobre a fronteira de produção, sendo, portanto, eficiente no sentido de Farrel (1957).

De acordo como Farell (1957), pode-se utilizar o conceito de função distância orientada pelo produto, para um dado conjunto de insumos, como uma medida de eficiência técnica de produção. Esta medida refere-se à distância entre o produto observado e o produto potencial máximo, sendo medida como uma proporção deste último. Dito de outro modo, a função distância é a máxima expansão proporcional do produto de modo a torná-lo eficiente. Assim sendo, seja $f(x: \beta)$ a função estocástica translog em (1). Desde que o produto e as variáveis explicativas estão em logaritmo, tem-se que $e^{u_{i t}}=Y_{i t} / f(x ; \beta) e^{v_{i t}}$, em que $Y_{i t}$ é o valor do produto em nível. Fazendo-se relação com o conceito e eficiência técnica de Farrel (1957), tem-se que $D_{o}^{t}\left(x^{t}, y^{t}\right)=e^{u_{i t}}=Y_{i t} / f(x ; \beta) e^{v_{i t}}$.

12 A função distância também pode ser definida orientada pelo insumo. Denotando-a por $D_{i}\left(x^{t}, y^{t}\right)$, temse que $D_{i}\left(x^{t}, y^{t}\right)=\sup \left\{\rho:\left(x^{t} / \rho, y^{t}\right) \in L\left(y^{t}\right)\right\}$ em que o conjunto de insumos $L\left(y^{t}\right)$ representa todos os vetores de insumos $x_{t}$, que podem produzir o vetor de produtos $y_{t}$. Isto é, $L\left(y^{t}\right)=\left\{x^{t}: x^{t}\right.$ pode produzir $\left.y^{t}\right\}$. Ela mede a máxima contração do vetor de insumos $x^{t}$, de forma que $y^{t}$ ainda possa ser produzido. 


\section{4 Índice de Produtividade Total de Malmqüist}

O índice de produtividade total de Malmqüist, orientado pelo produto aqui denotado por PTFM, para uma dada tecnologia de referência no período de tempo, $\mathrm{t}$, de acordo com Caves, Christensen e Diewert (1982a), é apresentado no formato proposto por Färe et al. (1994) da seguinte forma:

$$
P T F M=\left[\frac{D_{o}^{t+1}\left(y^{t+1}, x^{t+1}\right)}{D_{o}^{t}\left(y^{t}, x^{t}\right)}\right]\left[\frac{D_{o}^{t}\left(y^{t+1}, x^{t+1}\right)}{D_{o}^{t+1}\left(y^{t+1}, x^{t+1}\right)} x \frac{D_{o}^{t}\left(y^{t}, x^{t}\right)}{D_{o}^{t+1}\left(y^{t}, x^{t}\right)}\right]^{1 / 2}
$$

em que as distâncias que compõem este índice são calculadas de acordo com a definição (4).

O primeiro termo do lado direito de (5) mede a variação de eficiência técnica relativa, ou seja, a distância do produto observado em relação ao produto potencial máximo entre os períodos $t$ e $t+1$. Este termo quantifica a variação de eficiência técnica de produção (VET) e é conhecido na literatura como efeito cathing-up ou efeito aproximação da unidade produtiva na direção da fronteira de produção. O segundo quantifica o deslocamento da fronteira de produção devido ao progresso técnico entre os períodos $t$ e $t+1$, avaliado em $x^{t}$ e $x^{t+1}$. Este termo representa exatamente a variação tecnológica $(V T)$. Assim sendo, tem-se que:

$$
\begin{aligned}
& V E T=\left[\frac{D_{o}^{t+1}\left(y^{t+1}, x^{t+1}\right)}{D_{o}^{t}\left(y^{t}, x^{t}\right)}\right] \\
& V T=\left[\frac{D_{o}^{t}\left(y^{t+1}, x^{t+1}\right)}{D_{o}^{t+1}\left(y^{t+1}, x^{t+1}\right)} \times \frac{D_{o}^{t}\left(y^{t}, x^{t}\right)}{D_{o}^{t+1}\left(y^{t}, x^{t}\right)}\right]
\end{aligned}
$$

Portanto, para se calcular a PTFM, VET e $V T$ é preciso primeiramente calcular as distâncias $D_{o}^{t}\left(x^{t}, y^{t}\right), D_{o}^{t+1}\left(x^{t+1}, y^{t+1}\right), D_{o}^{t}\left(x^{t+1}, y^{t+1}\right)$ e,$D_{o}^{t+1}\left(x^{t}, y^{t}\right)$, de acordo com a expressão (4).

Caves et al. (1982b) demonstram que sob certas condições o índice de produtividade de Malmqüist, expressão (5), é equivalente ao índice de Tornqvist (cujo cálculo de- 
pende de informações sobre participações na renda, receita ou custo). Mostram, ainda, que este último índice é "exato" no caso da tecnologia translog. ${ }^{13}$

\section{DADOS AMOSTRAIS, ESTIMAÇÃO E RESULTADOS}

\subsection{Dados Amostrais}

Os dados foram extraídos de três fontes básicas: Penn World Table 6.1 (PWT 6.1) ${ }^{14}$ (Heston, Summers e Aten, 2002), World Development Indicators (WDI), fornecido pelo Banco Mundial (BIRD), e The International Monetary Fund's Dissemination Standards Bulletin Board (DSBB-FMI), publicado pelo Fundo Monetário Internacional (FMI).

As variáveis Produto por trabalhador (Real GDP per worker), Trabalho (Worker), Gasto de consumo do governo (Gorvernment share of RGDPL), Desvios dos preços locais da PPP (Price level of Gross Domestic Product) e Grau de abertura (Openness in constant prices) foram retiradas da Penn World Table 6.1 (PWT 6.1).

A variável taxa de inflação (Inflation, consumer price (annual \%)) foi obtida do World Development Indicators (WDI).

No caso das informações sobre taxa de inflação, a falta de dados para o Brasil e Nicarágua no WDI teve que ser obtida de outras fontes. Em relação ao Brasil, em face da existência de uma série extensa da variável inflação, medida a partir de índices de preços ao consumidor, adotou-se como referência o Índice Geral de Preços - Disponibilidade Interna (IGP-DI), apurado pela Fundação Getúlio Vargas (FGV) e divulgado na revista Conjuntura Econômica. Para a Nicarágua, os dados sobre inflação, medidos com base em índice de preços para o consumidor, foram obtidos do DSBB-FMI.

Utilizam-se dados das séries de produto e de fatores de produção em nível na estimação da fronteira estocástica em vez do procedimento tradicional de considerar essas variáveis sob a forma de taxas de variação. Este procedimento se justifica pelo fato de que o uso de preços internacionais para ajustar as diferenças no poder de compra das moedas de diferentes países tende a superestimar as taxas de crescimento dos países ricos e a subestimar as dos países mais pobres. Assim, evita-se a introdução de viés nos dados e, em consequiência, sobre as estimações. (Nuxoll, 1994).

13 O termo "exato" foi dado por Diewert (1976) para classificar um índice de quantidade que mantém uma correspondência exata com a tecnologia especificada, mas que pode ser calculado sem a necessidade de se estimar os parâmetros da forma funcional relativa àquela tecnologia. No caso do índice de Tornqvist, há uma correspondência exata com a função translog. Sobre este assunto, veja-se, ainda, Coelli et al. (1998) e Kohli (2004).

14 Penn World Table 6.1 é uma atualização em andamento da versão PWT 5.6. 
Deve-se ainda acrescentar que no contexto de fronteira de produção esse procedimento de estimação usando as variáveis em nível é relevante, pois as taxas de crescimento do Produto Interno Bruto, em termos reais, variam mais acentuadamente que as taxas de crescimento do capital (físico e humano) e do fator trabalho ao longo do tempo. Assim, a relação entre o produto e os fatores de produção fica enfraquecida. De outra parte, as freqüências do ciclo de negócios do processo de produção podem ser dominadas pelas variações da capacidade de utilização dos fatores de produção, que são de difícil medição, notadamente em países em desenvolvimento. Essas flutuações também têm reflexo direto sobre as medidas de eficiência técnica, que se acentuariam à medida que fossem utilizadas as variáveis especificadas em primeira diferença.

A amostra é composta de dados anuais dos países da América Latina no período compreendido entre os anos de 1961 e 1990. A amostra total é constituída de 570 observações sob a forma de um painel balanceado.

Em relação ao número de países integrantes da amostra, a disponibilidade de dados estatísticos foi o fator determinante na sua definição final. Por outro lado, o estabelecimento do ano de 1990 como limite superior da amostra foi determinado pela falta de informações sobre capital físico dos países a partir daquele ano. ${ }^{15}$

\subsection{Estimação da Fronteira de Produção}

As estimativas dos parâmetros da fronteira de produção, equação (1), estão apresentadas na Tabela 2. Todos os parâmetros estimados são estatisticamente significantes no nível de $5 \%$.

O sinal positivo do parâmetro $\theta_{1}$ indica que ocorreu progresso tecnológico, embora sua magnitude não tenha sido expressiva em termos numéricos. Já o sinal negativo de $\theta_{2}$ mostra uma desaceleração na variação do progresso técnico.

$\mathrm{O}$ indicador de ineficiência técnica $\gamma$ apresenta o valor de 0,89. Neste sentido, 89\% da variância total do erro composto de (1) é explicada pela variância da ineficiência técnica. A estatística da Razão de Verossimilhança $(\lambda)$ do teste de hipóteses para o parâmetro $\gamma$ tem uma distribuição aproximadamente qui-quadrado mista, com graus de liberdade iguais ao número de restrições independentes, correspondendo, neste caso, a cinco graus de liberdade. Examinando-se a hipótese nula de inexistência de efeitos de ineficiência técnica na função de produção (1) conclui-se que ela deve ser

15 Os dados sobre estoque de capital dos países são ainda bastante precários e sujeitos a muitas críticas. Em geral, as séries de capital são construídas por meio de estimativas obtidas a partir do investimento bruto em cada ano, utilizando-se a técnica de inventários. Costuma-se também usar proxies para o capital. Neste trabalho, utilizam-se as informações apuradas pelo grupo do World Development Indicators (WDI), do Banco Mundial (BIRD). 
rejeitada, uma vez que o valor calculado para estatística $\lambda(\lambda=201,16)$ supera o valor crítico do teste no nível de significância de $5 \%$ (11,91), obtido na Tabela 1 de Kodde e Palm (1986, p. 1246). Isto mostra a importância de incorporar a ineficiência técnica ao modelo.

\section{TABELA 2 - ESTIMATIVAS DOS PARAMMETROS DA FRONTEIRA ESTOCÁSTICA DE PRODUÇÃO}

\begin{tabular}{lcc}
\hline PARÂMETROS/VARIÁVEIS & ESTIMATIVA & VALOR-t \\
\hline$\theta_{1}(\mathrm{t})$ & 0,1263 & 12,50 \\
$\theta_{2}\left((\mathrm{l} / 2) \mathrm{t}^{2}\right)$ & $-0,001$ & $-7,18$ \\
$\beta_{0}(\ln \mathrm{K})$ & $-2,819$ & $-9,13$ \\
$\beta_{1}(\mathrm{t} \ln \mathrm{K})$ & $-0,012$ & $-11,00$ \\
$\lambda_{0}(\ln \mathrm{L})$ & 3,819 & 12,39 \\
$\lambda_{1}(\mathrm{t} \ln \mathrm{L})$ & 0,012 & 10,96 \\
$\eta_{1}((\mathrm{l} / 2) \ln \mathrm{K} \ln \mathrm{K})$ & 0,378 & 10,87 \\
$\eta_{2}(\ln \mathrm{K} \ln \mathrm{L})$ & $-0,378$ & $-10,88$ \\
$\eta_{3}((\mathrm{l} / 2) \ln L \ln \mathrm{L})$ & 0,378 & 10,87 \\
$\delta_{0}($ intercepto $)$ & $-0,144$ & $-1,86$ \\
$\delta_{1}\left(\mathrm{z}_{1}-\right.$ gastos de consumo do governo) & 1,454 & 6,96 \\
$\delta_{2}\left(\mathrm{z}_{2}-\right.$ desvio dos preçOs locais em relação à PPP) & $-0,131$ & $-2,40$ \\
$\delta_{3}\left(\mathrm{z}_{3}-\right.$ taxa de inflação) & 0,049 & 3,93 \\
$\delta_{4}\left(\mathrm{z}_{4}-\right.$ grau de abertura) & $-0,189$ & $-2,61$ \\
\hline$\sigma_{\varepsilon}^{2}$ & 0,019 & 4,55 \\
$\gamma$ & 0,892 & 21,20 \\
Eficiência Média & 0,894 & \\
Log da Função de Verossimilhança & 583,84 & \\
\hline
\end{tabular}

*Os efeitos fixos dos países não são apresentados na Tabela.

Quanto aos parâmetros estimados das variáveis que explicam a ineficiência técnica, todos eles foram estatisticamente significantes no nível de 5\%, exceto o intercepto, sendo seus sinais consistentes com os valores esperados, o que se discute a seguir.

O coeficiente da variável gasto corrente do governo $\left(z_{1}\right)$ é positivo e significante, sugerindo que elevadas participações desse componente dos gastos na composição do dispêndio agregado dos países da América Latina, em média, introduzem ineficiência na economia. Assim, países com elevados gastos correntes tendem a ser menos eficientes. (Klein e Luu, 2001). Esse resultado pode ter como explicação o fato de que a pressão dos gastos públicos mais elevados resulta em um efeito de deslocamento nos investimentos produtivos (crowding-out), gerando distorções na alocação de recursos.

A variável desvios dos preços locais em relação à PPP $\left(z_{2}\right)$ tem coeficiente negativo e significante. Assim, países da região que tenham adotado políticas comerciais baseadas na desvalorização do câmbio real lograram êxito em reduzir o seu grau de ineficiência. 
Desvalorizações reais do câmbio induzem a um volume maior de exportação e a uma conseqüente elevação do grau de utilização da capacidade instalada do setor externo, com reflexos na expansão da demanda interna. Esse efeito será tanto maior quanto mais significativa for a participação do setor externo na economia local.

O coeficiente da taxa de inflação $\left(z_{3}\right)$ mostrou-se positivo e significante, sendo, portanto, consistente com a vasta literatura empírica que mostra os efeitos danosos sobre a economia de altas taxas de inflação. (Klein e Luu, 2001; De Gregório e Lee, 1999). Processos inflacionários inibem o comércio e desestimulam a formação de capital, na medida em que introduzem distorções na formação dos preços relativos. Nesse aspecto particular, deve-se observar que vários países da América Latina experimentaram extensos períodos de acirrados processos inflacionários com impactos negativos sobre o desempenho de suas economias.

No caso específico do Brasil, a década de 1980 caracterizou-se por um persistente processo inflacionário que motivou a adoção de vários planos de estabilização econômica sem, contudo, conseguir-se êxito quanto ao efetivo controle do processo inflacionário.

A variável denominada de grau de abertura $\left(z_{4}\right)$ tem coeficiente negativo e significante, indicando, portanto, que países da região com economias mais abertas apresentaram melhor desempenho relativamente ao grau de ineficiência técnica. Este resultado é consistente com a explicação de que economias com maior grau de abertura têm acesso a bens intermediários de preços mais baixos, a novas tecnologias e a mercados mais amplos.

\section{TABELA 3 - TESTE DA RAZÃO DE VEROSSIMILHANÇA DOS PARÂMETROS DA FRONTEIRA ESTOCÁSTICA DE PRODUÇÃO}

\begin{tabular}{llccc}
\hline Teste & Hipótese Nula & Valor de I & Valor Crítico & Decisão (Nível de 5\%) \\
\hline 1 & $\mathrm{H}_{0}: \beta_{1}=\lambda_{1}=\eta_{1}=\eta_{2}=\eta_{3}=0$ & 77,16 & 5,99 & Rejeita $\mathrm{H}_{0}$ \\
2 & $\mathrm{H}_{0}: \delta_{1}=\delta_{2}=\delta_{3}=\delta_{4}=0$ & 119,84 & 9,49 & Rejeita $\mathrm{H}_{0}$ \\
3 & $\mathrm{H}_{0}: \theta_{1}=\theta_{2}=0$ & 141,24 & 5,99 & Rejeita $\mathrm{H}_{0}$ \\
\hline
\end{tabular}

${ }^{*} \lambda$ : teste estatístico da razão de verossimilhança no qual $\lambda=-2\{\log$ [verossimilhança(H0)] $\log [$ verossimilhança $(\mathrm{Hl})]\}$. Este teste tem uma distribuição aproximadamente qui-quadrado com graus de liberdade iguais ao número de restrições independentes.

Na Tabela 3 apresentam-se alguns testes estatísticos construídos com a finalidade de se verificar a consistência de hipóteses específicas relacionadas à fronteira de produção estocástica (1). O primeiro teste refere-se ao teste de adequação da forma funcional translog relativamente à forma funcional mais restritiva Cobb-Douglas. Assim, testase a hipótese de que todos os coeficientes de segunda ordem e os coeficientes dos produtos cruzados de (1) são todos iguais a zero. $\mathrm{O}$ valor da razão de verossimilhança, 77,16 , supera o valor crítico da estatística $\chi_{(6)}^{2}$ com nível de significância de $5 \%$. Com 
isso, rejeita-se a especificação na forma de uma função Cobb-Douglas em favor do modelo translog especificado.

O segundo teste de hipóteses refere-se ao teste de significância conjunta dos parâmetros das variáveis que explicam a ineficiência técnica. O resultado rejeita a hipótese de que os parâmetros são simultaneamente iguais a zero.

O último teste examina a estabilidade da fronteira de produção com relação à variável tempo, ou seja, verifica a presença ou não de progresso tecnológico. O resultado do teste rejeita a hipótese nula de que não houve progresso técnico.

\section{EFICIÊNCIA TÉCNICA, PROGRESSO TÉCNICO E PRODUTIVIDADE TOTAL DOS FATORES}

As estimativas das taxas de variação média da VET, VT e PTFM relativas a todos os países da amostra, no período compreendido entre os anos de 1961 e 1990, encontram-se apresentadas na Tabela 4.

TABELA 4 - PTFM, VET E VT : VARIAÇÃO MÉDIA ANUAL - AMÉRICA LATINA, 1961-1990 (\%)

\begin{tabular}{lccc}
\hline PAíSES & PTFM & VET & $V T$ \\
\hline Argentina & 0,34 & 0,29 & 0,05 \\
Bolívia & 0,28 & 0,15 & 0,13 \\
Brasil & 0,78 & 0,48 & 0,30 \\
Chile & 0,35 & 0,02 & 0,33 \\
Colômbia & 0,14 & 0,07 & 0,07 \\
Costa Rica & 0,11 & $-0,07$ & 0,19 \\
Rep. Dominicana & 0,20 & 0,31 & $-0,10$ \\
Equador & 0,45 & 0,44 & 0,00 \\
El Salvador & $-0,51$ & $-1,31$ & 0,82 \\
Guatemala & 0,03 & $-0,04$ & 0,07 \\
Honduras & 0,05 & 0,06 & $-0,01$ \\
Jamaica & 0,23 & 0,21 & 0,02 \\
México & 0,21 & 0,17 & 0,04 \\
Nicarágua & $-0,92$ & $-2,36$ & 1,48 \\
Paraguai & 0,49 & 0,57 & $-0,09$ \\
Peru & $-0,19$ & $-0,63$ & 0,44 \\
Trinidad y Tobago & $-0,09$ & $-0,33$ & 0,24 \\
Uruguai & 0,27 & $-0,03$ & 0,30 \\
Venezuela & 0,10 & $-0,25$ \\
\hline & 0,36 & \\
\hline 1961 - 1990 & Média da Amostra & & 0,21 \\
1961 - 1974 & 0,12 & $-0,09$ & 0,10 \\
1975 - 1990 & 0,18 & 0,08 & 0,31 \\
\hline
\end{tabular}

Fonte: Valores calculados pelos autores. 
Verificando, inicialmente, o comportamento da VET dos países da região, em termos médios, ${ }^{16}$ de acordo com os dados da Tabela 4 e Figura 2, identifica-se a ocorrência de um choque adverso a partir de 1974, resultando em uma significativa perda de eficiência técnica, cuja duração é de aproximadamente três anos, prolongando-se até 1976. A razão para essa brusca e persistente queda de eficiência técnica na região deve estar provavelmente relacionada à crise do petróleo que eclodiu no final de 1973.

FIGURA 2 - VARIAÇÃO MÉDIA DA PTFM - ÍNDICE DE MALMQÜIST AMÉRICA LATINA, 1960-1990

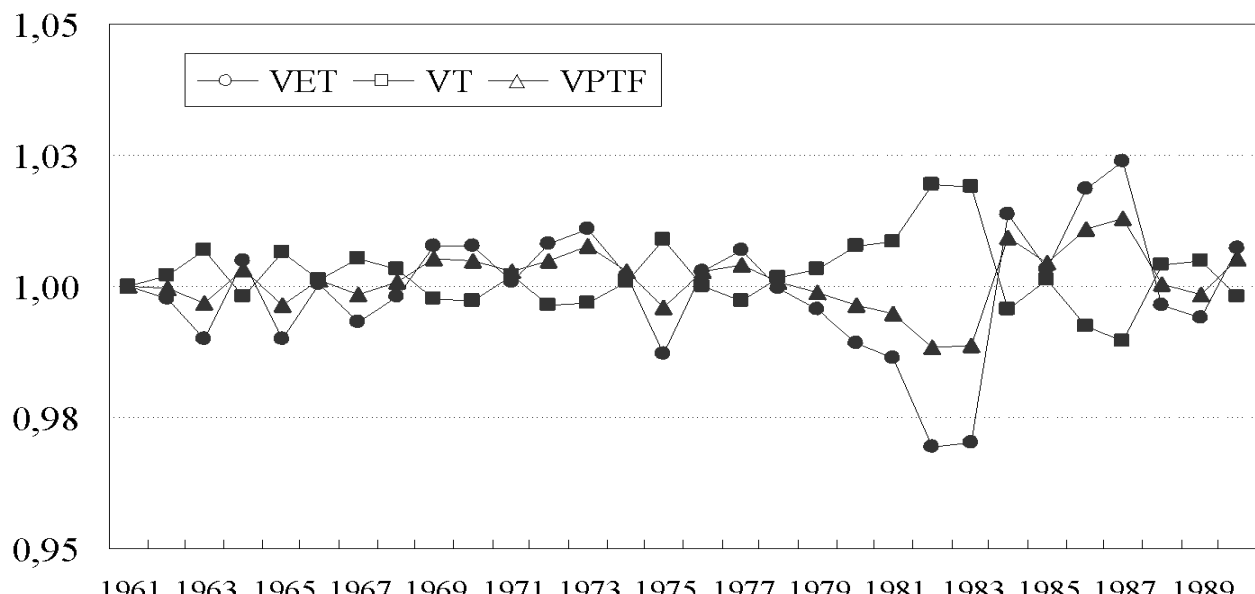

Em 1979, quando se dá o segundo choque do petróleo, observa-se novamente perda de eficiência técnica da economia latino-americana, que se prolonga até 1984, sendo que o ano de 1983 é marcado como o momento em que a região alcança o seu pior desempenho. Nesse período, além do choque do petróleo, a crise da dívida externa que se abateu sobre a maioria dos países da região constituiu-se, certamente, em um importante fator explicativo adicional na magnitude e na extensão desse desempenho. Observa-se, no entanto, que entre 1985 e 1988 há efetiva melhoria no comportamento da VET.

Examinado o desempenho da VET dos países em termos de taxas médias de crescimento na Tabela 4 , observa-se que aqueles que apresentaram as maiores taxas foram o Paraguai (0,57\%), Brasil (0,48\%), Equador (0,44\%), Venezuela (0,36\%), República Dominicana $(0,31 \%)$ e Argentina $(0,29 \%)$. Já os seis países com os piores desempenhos no período foram os seguintes: Nicarágua $(-2,36 \%)$, El Salvador $(-1,31 \%)$,

16 Trata-se da média geométrica simples. Não há ponderação pelo peso do PIB dos países. 
Peru $(-0,63 \%)$, Trinidad y Tobago $(-0,33 \%)$, Costa Rica $(-0,07 \%)$ e Guatemala $(-0,04 \%)$.

Por último, como mostra a Figura 3, pode-se observar uma tendência, ao longo do tempo, de aumento da dispersão da PTFM e de seus componentes, VET e VT, para o conjunto dos países latino-americanos, que passa a se manifestar mais claramente a partir do ano de 1973.

FIGURA 3 - EVOLUÇÃO DOS DESVIOS PADRÃO: VET, VT E PTFM AMÉRICA LATINA, 1960-1990

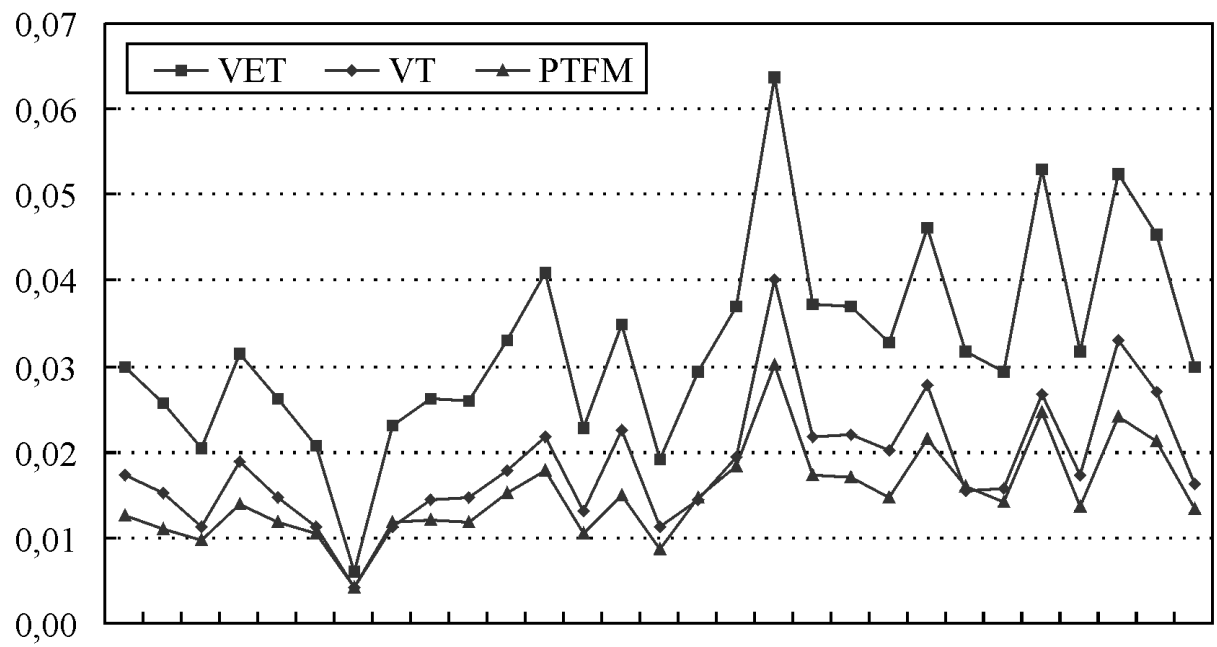

O exame do comportamento da $V T$, de acordo com a Tabela 4, mostra que houve uma variação positiva de $0,21 \%$ em termos médios para a amostra de países no período compreendido entre 1961 e 1990. Observam-se duas fases: no período entre 1961 e 1974 ocorre efetivamente uma variação positiva, em que o crescimento médio para a amostra é de 0,10\%; na segunda fase, de 1975 a 1990, os resultados mostram uma taxa de variação positiva de $0,31 \%$, sendo, portanto, superior à da primeira fase. É interessante notar que, ao contrário do que ocorreu com a VET, nos anos em que ocorreram os dois choques de petróleo a $V T$ apresentou variações positivas.

Os dados desagregados da VT na Tabela 4, considerados em termos de taxas médias de crescimento no período integral, mostram que os países que apresentaram maiores variações positivas foram Nicarágua (1,48\%), El Salvador $(0,82 \%)$, Peru $(0,44 \%)$, Chile $(0,33 \%)$, Brasil $(0,30 \%)$ e Uruguai $(0,30 \%)$. Os países classificados com os piores desempenhos foram: Venezuela $(-0,25 \%)$, República Dominicana $(-0,10 \%)$, Paraguai $(-0,09) \%)$, Honduras $(-0,06 \%)$, e Jamaica $(0,02 \%)$. 
Em relação à $P T F M$, cuja variação é obtida a partir da multiplicação dos índices VET e $V T$, os dados estimados da Tabela 4 mostram que em termos médios há um crescimento da ordem de $0,12 \%$ no período. Este resultado foi influenciado, sobretudo, pelo comportamento da $V T$, redundando num efeito líquido positivo, embora pouco expressivo, para a PTFM.

Examinando-se o comportamento desagregado da PTFM observa-se que os melhores desempenhos em relação às variações médias anuais ficaram por conta do Brasil $(0,78 \%)$, Paraguai (0,49\%), Equador (0,45\%), Chile (0,35\%) e Argentina $(0,34 \%)$. Os países com as piores variações médias de crescimento da PTFM foram Nicarágua $(-0,92 \%)$, El Salvador $(-0,51 \%)$, Peru (-0,19\%), Trinidad y Tobago $(-0,09 \%)$ e Guatemala $(0,03 \%)$.

Vale ressaltar que as estimativas obtidas para a PTFM mostram-se bastante próximas dos valores encontrados em outros estudos empíricos que utilizam a abordagem tradicional da contabilidade de crescimento, apesar das diferenças metodológicas. Entre eles encontram-se os trabalhos de De Gregório e Lee (1999) e Senhadji (1999).

De Gregório e Lee (1999) estimam um crescimento da PTF muito pequeno, cerca de 0,1\%, em média, no período 1960 a 1990, relativamente a uma amostra de vinte e um países da América Latina. Entre esses países, os piores desempenhos, em termos de taxas de crescimento médias anuais negativas, foram a Nicarágua $(-1,5 \%)$, Trinidad e Tobago (-1\%), Argentina (-0,5\%), e Venezuela (-0,5\%). Já os maiores crescimentos médios foram do Equador (1,6\%), Colômbia (1,3\%), Bolívia (1,2\%), Chile $(0,9 \%)$ e Brasil (0,8\%).

Senhadji (1999), por sua vez, estima a PTF da América Latina e de outras regiões, no período de 1960 a 1994, segundo algumas hipóteses sobre valores da participação do capital físico no produto. $\mathrm{O}$ autor encontra um valor médio para a região situado em $-0,39 \%$, utilizando a estimação da função de produção em nível. Há, neste caso, uma pequena variação média negativa da PTF para uma amostra de países da região.

Desses resultados pode-se concluir que embora tenha ocorrido melhoria tecnológica na América Latina, no período compreendido entre 1961 e 1990, o resultado geral indica uma pequena variação na PTFM da região.

\section{CONCLUSÕES}

Há concordância, na literatura econômica, de que a acumulação de capital físico não é capaz de manter o processo de crescimento sustentado e que a fonte para a evolução 
e a prosperidade econômica no longo prazo reside no continuado aumento da PTF que, por sua vez, está associada à expansão do progresso técnico, de acordo com a metodologia tradicional adotada na quantificação da PTF.

$\mathrm{Na}$ abordagem aqui adotada, que difere da metodologia tradicional ao reconhecer a possibilidade de ineficiência técnica, a PTFM foi decomposta em VET e VT, permitindo a identificação da real contribuição do progresso tecnológico para o crescimento da PTFM.

Apurou-se que a taxa de variação acumulada da PTFM em termos da média do conjunto de países da América Latina, no período de 1961 a 1990, foi de 0,36\%. Esse desempenho pouco expressivo decorreu tanto da reduzida VT acumulada $(0,27 \%)$ quanto da pequena magnitude da $V E T$, que foi de $0,009 \%$. A reduzida importância do $V T$ já havia sido identificada na estimação da fronteira de produção, sendo posteriormente confirmada quando da construção dos índices de PTFM e na sua decomposição nos componentes de VET e VT.

Os piores desempenhos da PTFM, em termos médios e desagregados por países, ficaram por conta da Nicarágua $(-0,92 \%)$, El Salvador $(-0,51 \%)$, Peru $(-0,19 \%)$, Trinidad y Tobago $(-0,1 \%)$ e Guatemala $(0,3 \%)$. Os países com as mais elevadas taxas de crescimento médio foram o Brasil (0,79\%), Paraguai (0,49\%), Equador $(0,45 \%)$, Chile $(0,35 \%)$ e Argentina $(0,34 \%)$. É importante destacar que a decomposição da variação da $P T F$ em VET e VT permitiu constatar que nem todos os países com melhores desempenhos no crescimento da produtividade tiveram como fonte principal para esse resultado a $V T$, mas sim significativos ganhos de eficiência técnica que geraram efeitos finais positivos sobre a PTFM.

Além disso, como o crescimento da PTFM foi, em média, muito baixo para todos os países da amostra, pode-se inferir que a maior fonte de crescimento econômico da região decorreu do incremento na utilização de capital e trabalho e não da produtividade. (Young, 1994).

Quanto aos efeitos das variáveis macroeconômicas na explicação do componente de ineficiência técnica, constatou-se que os gastos correntes do governo e a inflação constituíram fatores explicativos para o aumento da ineficiência técnica desses países. Já o grau de abertura e os desvios dos preços locais em relação à paridade do poder de compra, esta última utilizada como uma aproximação da taxa de câmbio real, revelaram-se importantes fatores indicativos para o aumento da eficiência técnica.

Consistentemente com a explicação teórica, e a partir dos resultados obtidos, pôdese confirmar que o modesto crescimento do produto real per capita apresentado pela América Latina, nestes trinta anos (1961 a 1990), deveu-se, sobretudo, ao frustrante 
desempenho da PTFM, a qual apresentou, no período, uma variação positiva, mas de pequena expressão. O desempenho da eficiência técnica das economias latino-americanas, que apresentou fortes quedas principalmente na década de 1980, e o baixo nível de acumulação de progresso tecnológico contribuíram para este resultado. A VT mostrou-se insuficiente para compensar as perdas de VET apresentadas pela maioria dos países, principalmente nos anos 1980, quando provavelmente a crise da dívida realçou os grandes desajustes internos acumulados no período.

Uma possível e razoável explicação para o decepcionante desempenho da PTFM pode ter origem nos fundamentos que sustentaram a concepção da política de industrialização baseada na substituição de importações (ISI) e na forma de sua condução, adotada na maioria dos países da região a partir dos anos 1950 e 1960, tendo sua inspiração no pensamento da CEPAL. A proposição básica para o enfrentamento da dependência econômica da América Latina em relação aos países desenvolvidos tinha como pressuposto o crescimento econômico impulsionado pela acumulação do capital físico, tendo-se caracterizado, ainda, pelos seguintes aspectos: pouca ênfase nas políticas relacionadas à incorporação sistemática de inovações tecnológicas, reconhecimento das restrições à formação de poupança interna, grau elevado de protecionismo às indústrias nascentes e caráter introvertido do processo de desenvolvimento.

Com o rápido esgotamento do modelo, os países da região passaram então a enfrentar uma redução no dinamismo econômico inicial. Por outro lado, as reformas iniciadas em alguns deles nos anos 1970 não apresentaram resultados capazes de alterar a tendência de pouco dinamismo econômico. Deve-se ressaltar, no entanto, que embora esses indícios possam constituir uma explicação para o baixo desempenho da PTF, faz-se necessário analisar mais cuidadosamente estas relações de causa e efeito, o que não é permitido no atual modelo.

\section{REFERÊECIAS BIBLIOGRÁFICAS}

Aigner, D. J.; Lovell, C. A. K. Schmidt, P. Formulation and estimation of stochastic frontier production functions models. Journal of Econometrics, v. 6, p. 21-37, 1977.

Arrow, K. The economic implications of learning by doing. Review of Economic Studies, 20, p. 155-173, 1962.

Barro, R.; Sala-I-Martin, X. Technological diffusion, convergence, and growth. NBER Working Paper n ${ }^{\circ}$ 5151, 1995.

Bauer, P. W. Recent developments in the econometric estimation of frontiers. Journal of Econometrics, v. 46, p. 39-56, 1990.

Battese, G. E. Frontier production function and technical efficiency: a survey of empirical applications in agricultural economics. Agricultural Economics, v. 7, p. 185-208, 1992. 
Battese, G. E.; Coelli, T. J. A stochastic frontier production incorporating a model for technical inneficiency effects. Working Papers in Econometrics and Applied Statistics, N. 69, Departament of Econometrics, University of New England, Armidale, p. 22, 1993.

. A model for technical inefficiency effects in stochastic frontier production functions for panel data. Empirical Economics, 20, p. 325-332, 1995.

Cass, D. Optimum growth in an aggregative model of capital accumulation. Review of Economic Studies, 32, p. 233-240, 1965.

Caves, D. W.; Christensen, L. R.; Diewert, W. E. Multilateral comparisons of output, input and productivity using superlative index number. Economic Journal, 92, p. 73-86, 1982a.

. The economic theory of index numbers and the measurement of input, output and productivity. Econometrica, 50, p. 1393-1414, 1982 b.

Coelli, T. J. A guide to FRONTIER version 4.1: a computer program for stochastic frontier production and cost function estimation. CEPA Working Paper 07, 1996.

Coelli, T. J.; Rao, D. S. P.; Battese, G. E. An introduction to efficiency and productivity analysis. Kluwer Academic Publishers, 1998.

Conjuntura Econômica. Disponível em: http://www.fgv.br/ibre/cecon/redacao.asp. Acesso em 15/10/ 2002.

De Gregorio, J. Economic growth in Latin America. Journal of Development Economics, 39, p. 59-84, 1992.

De Gregorio, J.; Lee, Jong-Wha. Economic growth in Latin America: sources and perspectives. Global Network Conferences, Cairo, 1999.

Denison, E. F. Classification of sources of growth. Review of Income and Wealth, 18, p. $1-25,1972$.

Diewert, W. E. Exact and superlative index numbers. Journal of Econometrics, 4, p. 115-145, 1976.

Duffy, J.; Papageorgiou, C. A cross-country empirical investigation of the aggregate production function specification. Journal of Economic Growth, 5, p. 87-120, 2000 .

Easterly, W.; Levine, R. What have we learned from a decade of empirical research on growth? It's Not Factor Accumulation: Stylized Facts and Growth Models. World Bank Economic Review, v. 15, n. 2, p. 177-219, 2001.

Färe, R.; Grosskopt, S. M.; Zhang, Z. Productivity growth, technical progress and efficiency change in industrialized countries. American Economic Review, 64, p. 66-83, 1994.

Farrell, M. J. The measurement of productive efficiency. Journal of Royal Satatistical Society, Series A, CXX, Part 3, p. 253-290, 1957. 
Forsund, F. R.; Lovell, C. A. K.; Schmidt, P. A survey of frontier productivity functions and their relationship to efficiency measurement. Journal of Econometrics, v. 13, p. 5-25, 1980.

Foxley, A. Latin America experiments in neoconservative economics. Berkley, CA: University of California Press, 1983.

Fried, H. O.; Lovell, C. A. K.; Schmidt, S. S. (eds.), The measurement of productive efficiency: techniques and applications. New York: Oxford University Press, 1993.

Green, W. I. I. The econometric approach to efficiency analysis. In: Fried, H. O.; Lovell, C. A. K.; Schmidt, S. S. (eds.), The measurement of productivity efficiency: techniques and applications. New York: Oxford University Press, 1993, p. 68119.

Griliches, Zvi. The discovery of the residual: a historical note. Journal of Economic Literature, v. 34, n. 1, p. 1324-1330, sept. 1996.

Grosskopf, S. Efficiency and productivity. In: Fried, H. O.; Lovell, C. A. K.; Schmidt, S. S. (eds.), The measurement of productivity efficiency: techniques and applications. New York: Oxford University Press, 1993, p. 160-194.

Heston, A.; Summers, R.; Aten, B. Penn World Table Version 6.1 Center for International Comparisons at the University of Pennsylvania (CICUP), oct. 2002.

Hulten, Charles R. Total factor of productivity: a short biography. NBER Working Paper n. 7471, jan. 2000, 75p.

IMFUND/DSBB. Disponível em: http://dsbb.imf.org/Applications/web/dsbbhome/. Acesso em 15 jan 2003.

Klein, P. G.; Luu, H. Politics and productivity. Merril Lynch Capital Markets Bank Ltd., 2001.

Kneller, R.; Stevens, P. A. The specification of the aggregate production function in the presence of inefficiency. Economic Letters, 81, p. 223-226, 2003.

Kode, D. A.; Palm, F. C. Wald criteria for jointly testing equality and inequality restrictions. Econometrica, Notes and Comments, v. 54, n. 5, p. 1243-1248, 1986.

Kohli, U. An implicit Törnqvist index of real GDP. Journal of Productivity Analysis, 21, p. 337-353, 2004.

Koopmans, T. C. On the concept of optimal economic growth. In: The Economic approach to development planning. Amsterdam: North-Holland, 1965.

Kormendi, Roger C.; Meguire, Philip G. Macroeconomic determinants of growth: cross-country evidence. Journal of Monetary Economics, v. 16, n. 2, p. 141-163, 1985.

Landau, Daniel L. Government expenditure and economic growth: a cross-country study. Southern Economic Journal, v. 49, n. 3, p. 783-792, 1983. 
Lucas, R. E. On the mechanics of economic development. Journal of Monetary Economics, 22, p. 3-42, 1988.

Macedo, B. G. As idéias de Raúl Prebisch sobre a industrialização periférica:1949-1954. 1994. Dissertação (Mestrado), Campinas: IE/Unicamp, São Paulo.

Malmqüist, S. Index number and indiference curves. Trabajos de Estadistica, v. 4, n. 1, p. 209-42, 1953.

Meeusen, W.; van den Broeck. Efficiency estimation from COBB-DOUGLAS production with composed error. International Economics Review, 32, p. 715-723, 1977.

Miller, S.; Upadhyay, M. P. The effects of openness, trade orientation, and human capital on total factor productivity. Journal of Development Economics, v. 63, p. 399-423, 2000.

Nuxoll, D. A. Differences in relative prices and international differences in growth rates. American Economic Review, v. 84, n. 5, p. 1423-1436, 1994.

Ramos, J. Neoconservative economics in southern cone of Latin America, 1973-1983. Baltimore, M. D.: John Hopkins University Press, 1988.

Ramsey, F. P. A mathematical theory of saving. Economic Journal, 38, p. 543-559, 1928.

Reinhardt, N.; Peres, W. Latin America's new economics model: micro responses and economic restructuring. World Development, v. 28, n. 9, p. 1543-1566, 2000.

Romer, P. Increasing returns and long-run growth. Journal of Political Economy, 94, p. 1002-1037, 1986.

. Endogenous technological change. Journal of Political Economy, 98, part 2, p. S71-S102, 1990.

Schmidt, P. Frontier production function. Econometric Reviews, v. 4, p. 289-328, 1986.

Scully, Geral W. The size of the state, economic growth and the efficient utilization of national resources. Public Choice, v. 63, n. 2, p. 149-164, nov. 1989.

Sheshinski, E. Optimal accumulation with learning-by-doing. In: Shell, K. (ed.), Essays on the theory of optimal economic growth. Cambridge: MIT press, 1967.

Senhadji, A. Sources of economic growth: an extensive growth accounting exercise. IMF Working Paper, WP/99/77, 1999.

Solow, R. M. A contribution to the theory of economic growth. Quarterly Journal of Economics, v. 70, n. 1, p. 65-94, Feb. 1956.

. Technical change and the aggregate production function. Review of Economic and Statistics, 39, p. 312-320, 1957.

The World Bank Group/Economic Growth Research. Disponível em: http://www. worldbank.org/research/growth/GNDdata.htm. Acesso em 12 out. 2002. 
Wu, Y. Is China's economic growth sustainable?. A productivity analysis. China Economic Review, 11, p. 278-296, 2000.

Younc, A. The tyranny of numbers: confronting the statistical realities of the east asian growth experience. NBER Working Paper $n^{\circ}$ 4680, p. 1-39, 1994. 